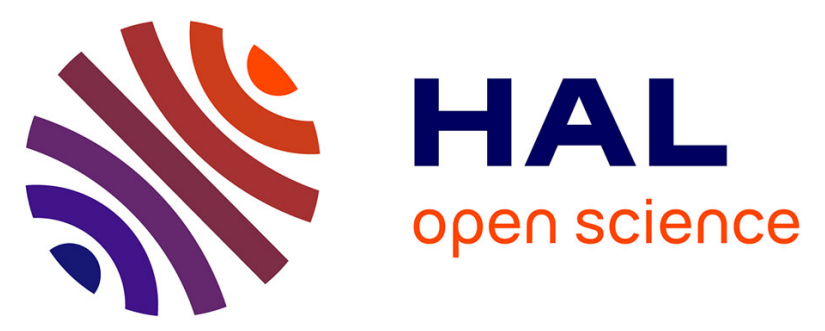

\title{
Synthesis of Bioinspired Curcuminoid Small Molecules for Solution-Processed Organic Solar Cells with High Open-Circuit Voltage
}

Florence Archet, Dandan Yao, Sylvain Chambon, Chahine Abbas, Anthony D

' Aléo, Gabriel Canard, Miguel-Armando Ponce-Vargas, Elena Zaborova, Boris Le Guennic, Guillaume Wantz, et al.

\section{To cite this version:}

Florence Archet, Dandan Yao, Sylvain Chambon, Chahine Abbas, Anthony D' Aléo, et al.. Synthesis of Bioinspired Curcuminoid Small Molecules for Solution-Processed Organic Solar Cells with High Open-Circuit Voltage. ACS Energy Letters, 2017, 2 (6), pp.1303-1307. 10.1021/acsenergylett.7b00157 . hal-01563209

\section{HAL Id: hal-01563209 \\ https://u-bourgogne.hal.science/hal-01563209}

Submitted on 7 Sep 2017

HAL is a multi-disciplinary open access archive for the deposit and dissemination of scientific research documents, whether they are published or not. The documents may come from teaching and research institutions in France or abroad, or from public or private research centers.
L'archive ouverte pluridisciplinaire HAL, est destinée au dépôt et à la diffusion de documents scientifiques de niveau recherche, publiés ou non, émanant des établissements d'enseignement et de recherche français ou étrangers, des laboratoires publics ou privés. 


\section{Synthesis of Bio-Inspired Curcuminoid Small}

\section{Molecules for Solution-Processed Organic Solar}

\section{Cells with High Open Circuit Voltage}

Florence Archet, ${ }^{\dagger}$ Dandan Yao, ${ }^{\dagger}$ Sylvain Chambon, ${ }^{\dagger}$ Mamatimin Abbas, ${ }^{\dagger}$ Anthony D'Aléo, ${ }^{\ddagger}$

Gabriel Canard,,$^{\ddagger}$ Miguel Ponce-Vargas,${ }^{\S}$ Elena Zaborova, ${ }^{\ddagger}$ Boris Le Guennic, ${ }^{* \S}$ Guillaume Wantz, *' and Frédéric Fages **t

${ }^{\dagger}$ Bordeaux INP, Université de Bordeaux, CNRS, IMS UMR 5218, 33400 Talence, France. ${ }^{\star}$ Aix Marseille Univ, CNRS, CINaM UMR 7325, 13288 Marseille Cedex 9, France. ${ }^{\S}$ Institut des Sciences Chimiques de Rennes, UMR 6226 CNRS, Université de Rennes 1, 263 Av. du Général Leclerc, 35042 Cedex Rennes, France.

AUTHOR INFORMATION

Corresponding Author

*boris.leguennic@univ-rennes1.fr.*Guillaume.Wantz@enscbp.fr.*frederic.fages@univamu.fr.

ABSTRACT. Borondifluoride complexes of curcuminoid derivatives end-capped with triphenylamine groups were designed for solution-processed bulk-heterojunction organic solar cells. They were obtained very simply in a one-pot synthesis from cheap building blocks. 
Compared to push-pull systems based on boron difluoride complexes of hydroxychalcones, curcuminoids present the donor-acceptor-donor electronic structure and exhibit significantly improved chemical and thermal stability and photovoltaic performance. Indeed power conversion efficiency up to $4.14 \%$ and high open-circuit voltage over $1.0 \mathrm{~V}$ have been achieved using $\mathrm{PC}_{61} \mathrm{BM}$ as acceptor.

\section{TOC GRAPHICS}

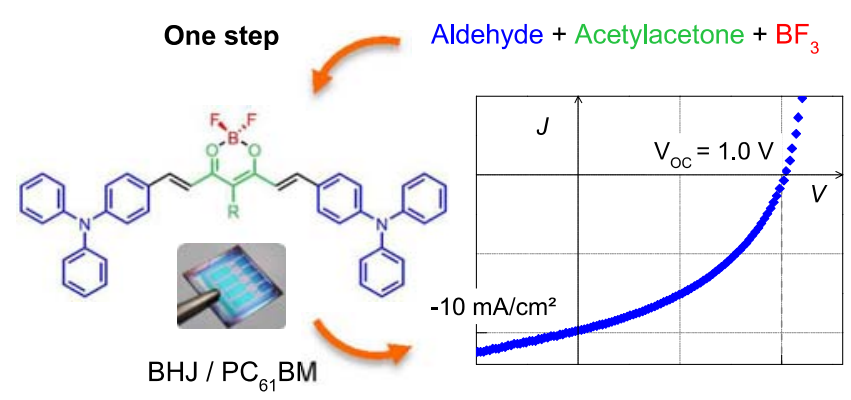


Organic solar cells (OSCs) hold great promise as renewable energy sources that are compatible with low-cost, large-area, solution-processed manufacturing on flexible substrates. Recently, bulk heterojunction (BHJ) OSCs, in which electron-donor and electron-acceptor materials are blended in an active layer, have demonstrated impressive power conversion efficiencies (PCEs) above $11 \%$ with polymers ${ }^{1,2}$ and around $10 \%-11 \%$ with small molecules. ${ }^{3,4}$ Keys to further progress in organic photovoltaics (OPVs) are the rational design of new materials, optimization of BHJ nanoscale morphology, improvement of device architectures, fabrication procedures, and device lifespan. As compared to their polymer counterparts, $\pi$-conjugated small molecules with well-defined structures are recognized as versatile donor components for the construction of BHJs using solution processes, such as roll-to-roll printing. To be economically viable, however, industrial application of small-sized molecular donors requires rapid development of costeffective, green synthetic methodologies that allow the scalable production of high-purity materials. $^{5,6}$

Molecular donors with high molar absorption coefficient and optical band gap matching the solar spectrum are generally designed to feature intramolecular charge transfer by covalently connecting donor (D) and acceptor (A) units in the conjugated backbone. These complex targets are obtained via linear multistep syntheses that include desymmetrization and metal-catalyzed cross-coupling of building blocks. ${ }^{7-10}$ Contamination may occur, due to trace metals and organic side-products that are difficult to remove. As a result, the synthetic effort is not often rewarded by reasonable overall yields. Actually, recent reports do stress scalability and purification of those conjugated materials as major issues to overcome in the future. ${ }^{5,6,10-12}$

Nature uses conventional nucleophilic reactions to produce structurally complex $\pi$-conjugated molecules from simple natural precursors. This led us to envision a bio-inspired synthetic route 
in which metal-free ionic reactivity could be exploited for the straightforward generation of borondifluoride complexes of curcuminoids. Those D-A-D molecules are related to the curcumin natural pigment and represent versatile chromophores that capitalize on the strong electron acceptor strength of the chelate moiety containing the Lewis acid boron atom. ${ }^{13,14}$ In our initial reports, synthesis was based on two sequential steps, the aldol condensation providing the free ligand followed by $\mathrm{BF}_{2}$ complexation. Yet simple, this methodology was found to be cumbersome in the case of highly soluble ligands because their thorough purification required repetitive chromatographic steps prior to $\mathrm{BF}_{2}$ incorporation, thereby limiting drastically the amount of isolated material.

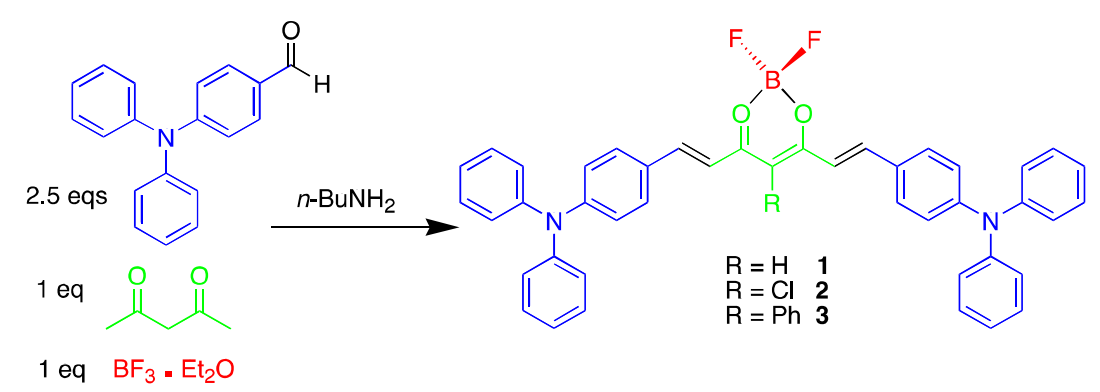

Scheme 1. One-pot synthesis of $\mathbf{1}-\mathbf{3}$

We report herein on three borondifluoride complexes of bis(triphenyl)amine (TPA)-containing curcuminoids, $\mathbf{1}-\mathbf{3}$ (Scheme 1) that act as efficient donor materials in solution-processed BHJ solar cells when blended with the electron acceptor [6,6]-phenyl- $\mathrm{C}_{61}$-butyric acid methyl ester $\left(\mathrm{PC}_{61} \mathrm{BM}\right)$. We show that the synthesis of compounds $\mathbf{1}-\mathbf{3}$ can be made as simple as possible. Indeed, they were obtained easily by mixing TPA carboxaldehyde, acetylacetone (or a mesosubstituted analogue) and borontrifluoride etherate (2.5:1:1 molar equivalents) in ethylacetate as solvent and in the presence of $n$-butylamine as a base (Scheme 1). We routinely ran batches affording between $700 \mathrm{mg}$ and $1 \mathrm{~g}$ of isolated pure material with yields above $70 \%$. We 
performed purification by a single flash chromatography column followed by washing the solids with distilled solvents (Supporting Information). Except for compound $\mathbf{2}$ that is sensitive to protic species in solution owing to the presence of the electron-withdrawing chlorine atom, $\mathbf{1}$ and 3 were found to be chemically and thermally stable. The thermogravimetric analysis of $\mathbf{1}$ did not show thermal degradation up to ca. $300{ }^{\circ} \mathrm{C}$ (Figure S1). This is an outstanding example of synthesizing a conjugated D-A-D molecule in a one-pot three-component reaction involving cheap commercially available chemicals. According to Roncali et al., ${ }^{5}$ compound $\mathbf{1}$ has a synthetic complexity index (SC) around 9 that represents a record value for efficient OPV materials reported so far.

Crystals of 1 were obtained after slow evaporation of dichloromethane (DCM) solution. They belong to the monoclinic space group P21/n with four molecules in the unit cell (Table S1). The conformation of $\mathbf{1}$ is not fully planar, with an angle of $33^{\circ}$ being noticed between the planes of the aromatic rings belonging to the curcuminoid backbone (Figure 1a). The molecules assemble into one-dimensional $\pi$-stacks along the crystallographic $\mathrm{b}$ axis with their main molecular planes being oriented parallel to one another and canted by ca. $40^{\circ}$ relative to the $\mathrm{b}$ axis (Figure S2). Borondifluoride complexes of curcuminoids have a ground-state (GS) dipole moment oriented perpendicularly to the long molecular axis, which explains the observed head-to-tail disposition of the dioxaborine rings. The face-to-face superimposition of the conjugated backbone of 1 occurs with alternate distances between the dioxaborine acceptor planes of $3.54 \AA$ and $3.07 \AA$, indicating a tight packing of the molecules. Interestingly, along a stack, TPA nitrogen atoms are aligned in straight rows, indicating favorable overlap between TPA moieties of adjacent molecules. Moreover, the crystal lattice contains voids that host highly disordered solvent molecules that could not be resolved. 


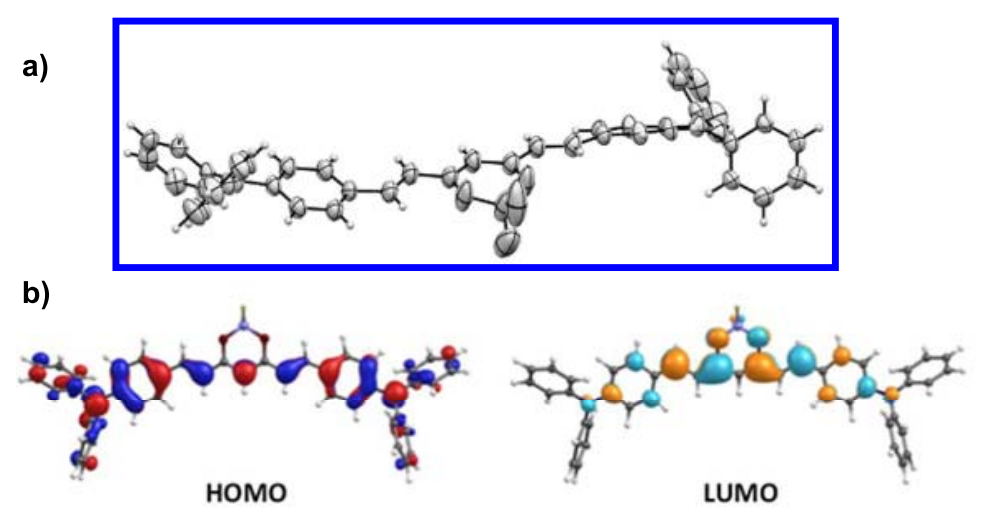

Figure 1. (a) Molecular structure (ORTEP) of compound 1 with displacement ellipsoids drawn at the $50 \%$ probability level. (b) Frontier molecular orbitals of $\mathbf{1}$ (contour threshold: 0.02 a.u.).

Compounds $\mathbf{1}$ - $\mathbf{3}$ display strong visible optical absorption in chloroform (CF) solution (Figure 2) and far-red fluorescence emission. The lowest-energy absorption band and fluorescence emission spectra of $\mathbf{1}-\mathbf{3}$ are broad and bathochromically shifted in solvents of increasing polarity (Figure S3). The excited state (ES) thus possesses a strong intramolecular charge transfer character with a dipole moment larger than that in the GS, which is confirmed by the Lippert-Mataga analysis of the solvatochromic shifts (Figure S4) and DFT calculations. The presence of the meso-phenyl substituent in $3\left(\lambda_{\max }=612 \mathrm{~nm}\right)$ causes a 20-nm red-shift of the absorption relative to $\mathbf{1}\left(\lambda_{\max }=594 \mathrm{~nm}\right)$, which was attributed to a conformational effect. ${ }^{12}$ Rather, the $50-\mathrm{nm}$ red-shift in the spectrum of $2\left(\lambda_{\max }=642 \mathrm{~nm}\right)$ stems from the enhanced electron accepting strength of the dioxaborine ring featuring the meso-chloro substituent, leading to a more polarized D-A-D $\pi$-system. 


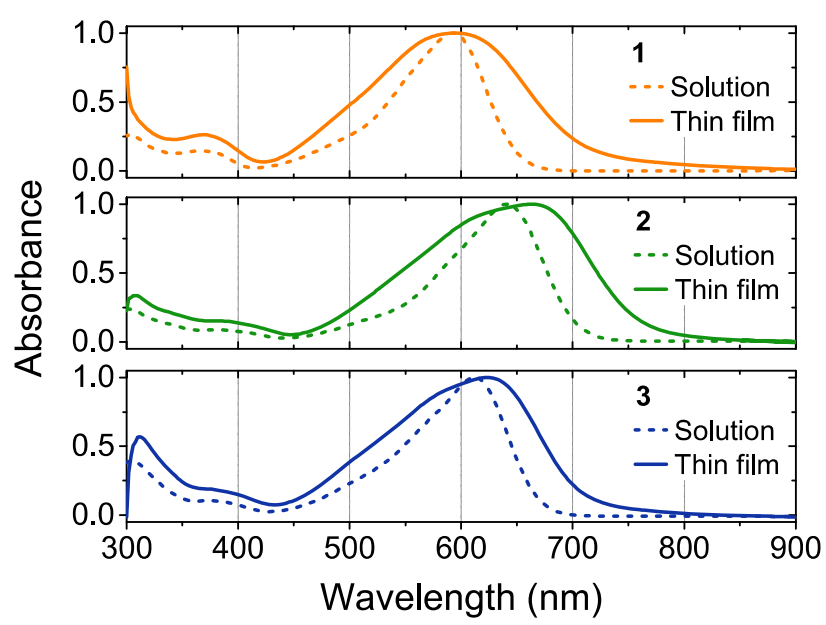

Figure 2. Electronic absorption spectra of $\mathbf{1}$ (orange), $\mathbf{2}$ (green) and $\mathbf{3}$ (blue) in CF solution (solid line) and thin film (dashed line), normalized with absorbance to 1.0.

The three compounds were found to be soluble in $\mathrm{CF}$, chlorobenzene (CB) and odichlorobenzene (DCB), allowing spin coating of solutions with concentrations over $10 \mathrm{mg} / \mathrm{mL}$. Compared to solution, thin-film absorption spectra of $\mathbf{1}-\mathbf{3}$ are significantly broadened (Figure 2 ), which indicates the occurrence of $\pi-\pi$ interactions as confirmed by the crystal structure of 1 . Unlike $1\left(\lambda_{\max }=592 \mathrm{~nm}\right)$, compounds $2\left(\lambda_{\max }=662 \mathrm{~nm}\right)$ and $3\left(\lambda_{\max }=624 \mathrm{~nm}\right)$ have thin film absorption spectra red-shifted relative to those recorded in solution. This may indicate a better planarization of the curcuminoid backbone or more pronounced interactions in the bulk owing to the presence of the meso group. Optical band gaps were estimated from the onset of the thin-film absorption spectra as $1.75 \mathrm{eV}, 1.64 \mathrm{eV}$ and $1.75 \mathrm{eV}$ for $\mathbf{1}, \mathbf{2}$ and $\mathbf{3}$, respectively. With the stronger electron-accepting unit, dye 2 displays a red-shifted onset and thus the narrowest gap (Table S2).

The energy levels of the frontier molecular orbitals (MOs) were estimated from cyclic voltammetry measurements in DCM by taking the onset of the oxidation and reduction waves (Figure S5 and Table S2). The three molecules present a similar value of $c a .-5.6 \mathrm{eV}$ for the 
energy of the highest occupied MO (HOMO) which is compatible with high open-circuit voltage $\left(V_{\mathrm{OC}}\right)$ when $\mathrm{PC}_{61} \mathrm{BM}$ is used as acceptor in OSCs. ${ }^{15}$ Consistent with the optical properties, the presence of the meso-chlorine atom lowers the lowest unoccupied MO (LUMO) of $2(-4.11 \mathrm{eV})$ by ca. $130 \mathrm{meV}$ relative to those of $\mathbf{1}$ and $\mathbf{3}$ found at $-3.96 \mathrm{eV}$. The positioning of the LUMOs of 1 and 3 is therefore well suited to photoinduced electron transfer into the LUMO of $\mathrm{PC}_{61} \mathrm{BM},{ }^{15}$ which is confirmed by the fluorescence quenching observed in thin-film blends (vide infra).

DFT/TD-DFT calculations were performed on $\mathbf{1}-\mathbf{3}$ (see computational details in ESI). The three molecules display identical contour plots of HOMOs and LUMOs (Figures $1 \mathrm{~b}$ and S6). HOMOs are mostly delocalized over the lateral groups with a significant contribution of TPA phenyl rings, whereas LUMOs are mainly located on the central dioxaborine acceptor moiety. The lowest energy (vertical) transition band consists mainly in HOMO $\rightarrow$ LUMO charge transfer transition (Table S3). This is consistent with the electronic density difference plots (Figure S6) that provide the difference between the electronic density of the lowest singlet ES and the GS. The energy level values obtained with optical, electrochemical, and theoretical approaches follow the same trends. For $\mathbf{1}$ and 3, GS and ES dipole moments amount to almost $11 \mathrm{D}$ and to over 12 D, respectively (Table S4). Overall dipoles moments are weakened for 2 (GS: 8.8 D; ES: $10.2 \mathrm{D})$ as a result of the local antiparallel dipole moment of the $\mathrm{C}($ meso $)-\mathrm{Cl}$ bond. These data are consistent with the solvatochromic absorption and fluorescence properties.

BHJ OSCs were fabricated using the following architecture: ITO/PEDOT:PSS/13: $\mathrm{PC}_{61} \mathrm{BM} / \mathrm{Ca} / \mathrm{Al}$ (Supporting Information) and tested under $100 \mathrm{~mW} / \mathrm{cm}^{2}$ illumination. Donor: $\mathrm{PC}_{61} \mathrm{BM}$ blends $(50: 50 \mathrm{w} / \mathrm{w})$ were spin-coated from $\mathrm{CB}$. The devices based on 2 and 3 present lower power conversion efficiencies (PCE $=0.9 \%$ and $1.1 \%$ respectively) compared to 1 that reached 3.1\% (Figure S7 and Table S5). The main difference arises from lower short-circuit 
current density $\left(J_{\mathrm{SC}}=8.9,4.3\right.$ and $5.0 \mathrm{~mA} / \mathrm{cm}^{2}$ for $\mathbf{1}, 2$ and $\mathbf{3}$ respectively). Hole mobilities $\left(\mu_{\mathrm{h}}\right)$ were determined from organic field-effect transistors (OFETs, Table S6). Results show that 2 and 3 present much lower $\mu_{\mathrm{h}}$ than $\mathbf{1}$, consistent with a higher $J_{S C}$ for the latter. Therefore, only devices based on 1:PC ${ }_{61} \mathrm{BM}$ were further optimized.

Figure 3 presents the impact of $1: \mathrm{PC}_{61} \mathrm{BM}$ blend ratio on $J_{\mathrm{SC}}$ and PCE. With increasing $\mathrm{PC}_{61} \mathrm{BM}$ concentration from 15 to $40 \mathrm{w} \%, J_{\mathrm{SC}}$ gradually rises up to $8 \mathrm{~mA} / \mathrm{cm}^{2}$.
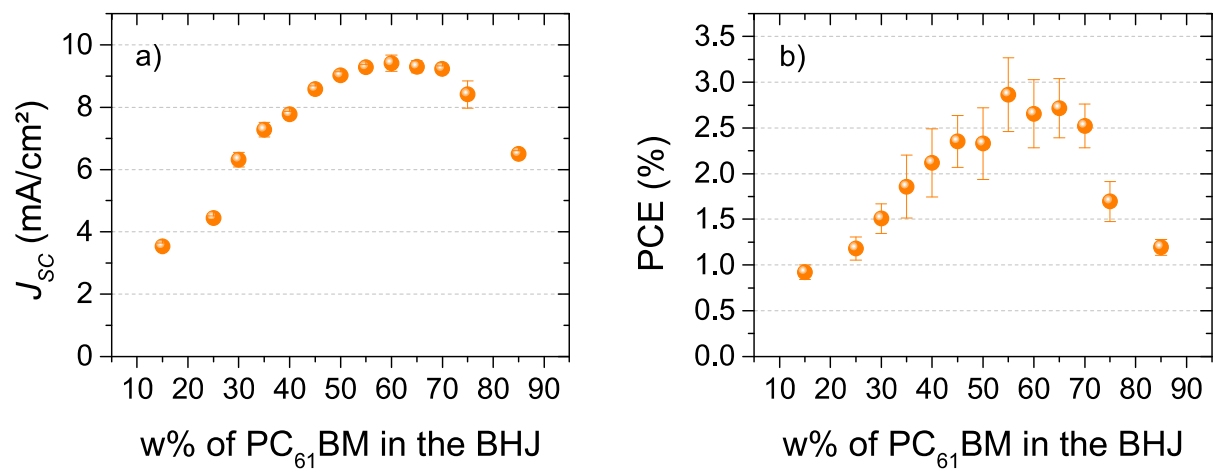

Figure 3. (a) $J_{\mathrm{SC}}$ and (b) PCE of BHJ OSCs based on 1:PC ${ }_{61} \mathrm{BM}$ with different blend ratios. Film thickness: $72-85 \mathrm{~nm}$.

Almost total fluorescence quenching occurs at $40 \mathrm{w} \%$ of $\mathrm{PC}_{61} \mathrm{BM}(100 \%$ quenching above 50 $\mathrm{w} \%$, Figure S8). As a result, with further addition of $\mathrm{PC}_{61} \mathrm{BM}$ up to $70 \mathrm{w} \%, J_{\mathrm{SC}}$ levels off at 8-9 $\mathrm{mA} / \mathrm{cm}^{2}$. Beyond this concentration, $J_{\mathrm{SC}}$ drops off because of the reduced optical absorption in $\mathbf{1}$. The low values of the fill factor $(\mathrm{FF}<40 \%$, Table S7) may stem from the unbalanced charge carrier mobilities (Table S6), $\mu_{\mathrm{h}}$ being found smaller than electron mobility. Devices with a weight ratio in a range from 55 to $65 \mathrm{w} \%$ of $\mathrm{PC}_{61} \mathrm{BM}$ provided the best value of PCE close to $3 \%$.

To explain the change of $J_{\mathrm{SC}}$ as a function of the blend ratio, we investigated 1-PC ${ }_{61} \mathrm{BM}$ blend morphologies using tapping mode atomic force microscopy (AFM, Figure S9). We observed the formation of large domains for low concentrations of $\mathrm{PC}_{61} \mathrm{BM}$ that disappear when $\mathrm{PC}_{61} \mathrm{BM}$ 
reaches $35 \mathrm{w} \%$. Between 35 and $75 \mathrm{w} \%$, smooth layers and small domains with similar sizes are observed and the morphology is independent of the blend composition. At low $\mathrm{PC}_{61} \mathrm{BM}$ content, because of their strong GS permanent dipole, molecules 1 self-assemble via electrostatic interactions as the main driving force. ${ }^{16,17}$ Therefore large domains of $\mathbf{1}$ are likely to prevail resulting in strong geminate recombination and, in turn, in a low $J_{\mathrm{SC}}$. From $35 \mathrm{w} \%$ to $75 \mathrm{w} \%$ of $\mathrm{PC}_{61} \mathrm{BM}$, the observed morphology is likely to favor exciton dissociation, leading to higher $J_{\mathrm{SC}}$. In that case, because both 1 and $\mathrm{PC}_{61} \mathrm{BM}$ possess a high dipole moment, ${ }^{18} \mathbf{1}: \mathrm{PC}_{61} \mathrm{BM}$ dipolar interactions may assist the formation of the intimately mixed blends. Such intermolecular interactions would also account for the red-shift of the thin film absorption $(\Delta \lambda=+10 \mathrm{~nm})$ noticed above $35 \mathrm{w} \%$ of $\mathrm{PC}_{61} \mathrm{BM}$ (Figure $\left.\mathrm{S} 10\right)$.

External quantum efficiencies $(\mathrm{EQE})$ recorded at different $1: \mathrm{PC}_{61} \mathrm{BM}$ blend ratios (Figure 4) support the previous observations and also provide further interesting information. As expected, increasing $\mathrm{PC}_{61} \mathrm{BM}$ loading from 30 to $70 \mathrm{w} \%$ leads to an increase of the contribution of both donor and acceptor materials. However, the EQE response of 1 starts decreasing beyond $70 \mathrm{w} \%$. Interestingly, at $50 \mathrm{w} \%$ of $\mathrm{PC}_{61} \mathrm{BM}$, a new band appears at $450 \mathrm{~nm}$ in the $\mathrm{EQE}$ spectrum and grows with a further increase of $\mathrm{PC}_{61} \mathrm{BM}$. This contribution can be attributed to the occurrence of $\mathrm{PC}_{61} \mathrm{BM}$ aggregates. ${ }^{19}$ Above this threshold concentration, the formation of larger $\mathrm{PC}_{61} \mathrm{BM}$ aggregates would create the conduction pathways for the electrons and improve the charge transport. Finally, the optimum performance is found for a balance between intermixed state for high exciton dissociation rate $\left(<70 \% \mathrm{PC}_{61} \mathrm{BM}\right)$ and large domains that favor charge transport $(>$ $\left.50 \% \mathrm{PC}_{61} \mathrm{BM}\right)$. 


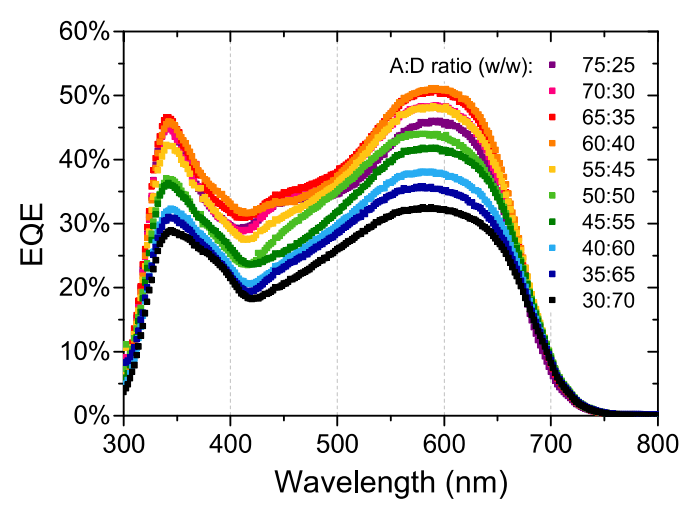

Figure 4. $\mathrm{EQE}$ curves of devices based on 1:PC ${ }_{61} \mathrm{BM}$ with different blend ratios.

In order to improve further the morphology, we fabricated $\mathrm{BHJ}$ OSCs using $\mathrm{CF}, \mathrm{CB}$ or $\mathrm{DCB}$ as solvents to spin coat the 1: $\mathrm{PC}_{61} \mathrm{BM}$ blend (ratio 35:65 w/w). Compared to devices spun from $\mathrm{CB}$ and DCB, CF-processed OSCs show a slightly improved $J_{\text {SC }}$ (Figure 5). Interestingly, the use of $\mathrm{CF}$ also leads to an increase of $V_{\mathrm{OC}}$ up to $1.0 \mathrm{~V}$ (Figure 5 and Table S8). The use of CF as a more volatile solvent influences the organization of both 1 and $\mathrm{PC}_{61} \mathrm{BM}$ and the degree of phase separation. This is supported by EQE spectra showing a higher contribution at $450 \mathrm{~nm}$, associated with $\mathrm{PC}_{61} \mathrm{BM}$ aggregates (Figure $\mathrm{S} 11$ ).

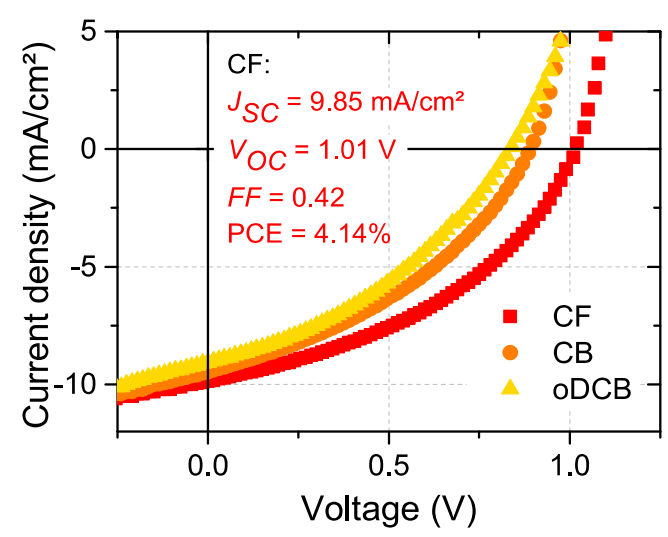

Figure 5. $J-V$ curves under $100 \mathrm{~mW} / \mathrm{cm}^{2}$ illumination of $\mathrm{BHJ}$ OSCs made with 1:PC ${ }_{61} \mathrm{BM}(35: 65$ w/w) spin-coated from CF (red), CB (orange) and DCB (yellow). 
Moreover, phase images of AFM measurements performed on blends processed from $\mathrm{CF}, \mathrm{CB}$ and DCB clearly show differences in morphology (Figure S12). DCB seems to give an intermixed active layer. Using CB leads to the formation of D and A domains which appear still too small to create efficient pathways for charges. Interestingly, using $\mathrm{CF}$ as a processing solvent, the D and A domains are larger and efficient percolation pathways are expected to build up. Such kind of morphology reduces bimolecular recombination losses, which could explain the higher $V_{\mathrm{OC}}{ }^{20}$ These results suggest that fast drying of the layer is favorable to the formation of an optimized BHJ with enhanced photocurrent. Finally, among the devices prepared in this study, the best performance was obtained at $65 \mathrm{w} \% \mathrm{PC}_{61} \mathrm{BM}$ using $\mathrm{CF}$ as the processing solvent, with $J_{\mathrm{SC}}=9.85 \mathrm{~mA} / \mathrm{cm}^{2}, V_{\mathrm{OC}}=1.01 \mathrm{~V}$ and $\mathrm{FF}=0.42$ giving an overall $\mathrm{PCE}$ of $4.14 \%$. In contrast, $V_{\mathrm{oc}}$ values obtained for boron difluoride complexes of hydroxychalcones as donor materials did not exceed $0.63 \mathrm{~V}^{14}$

In summary, we report the fabrication and initial characterization of BHJ OSCs based, for the first time, on borondifluoride complexes of curcuminoid derivatives as molecular donors and $\mathrm{PC}_{61} \mathrm{BM}$ as the acceptor. The synthesis of compounds $\mathbf{1}-\mathbf{3}$ is remarkably simple, cost effective and environmentally friendly and results in a record low synthetic complexity index ( $\mathrm{SC}=9$ for 1). Compared to related materials based on push-pull hydroxychalcone derivatives, ${ }^{14,21}$ curcuminoids feature a D-A-D extended $\pi$-conjugated system leading to significant overlap between TPA terminal moieties in the crystal. Moreover, unless it contains an electron withdrawing group such as the chlorine atom in $\mathbf{2}$, the acetylacetonate ligand moiety of the curcuminoids provides dioxaborine chelates that are more stable, both chemically and thermally, with respect to those obtained with hydroxychalcones. Therefore the results show the high 
potential of those D-A-D structures as molecular scaffolds on which to base the design of optimized donor materials for BHJ OSCs.

\section{ASSOCIATED CONTENT}

General methods, synthetic procedures, NMR spectra, UV-vis and fluorescence spectra, CV measurements, OFETs and OSCs fabrication and characterization data, single-crystal data, DFT calculations, crystallographic data (CIF).

\section{AUTHOR INFORMATION}

\section{Notes}

The authors declare no competing financial interest.

\section{ACKNOWLEDGMENT}

This work was supported by the French National Research Agency (ANR) ("Chalcones" Project, ANR-14-CE05-0035-01). This research used resources of the GENCI-CINES/IDRIS. We thank Dr. Michel Giorgi for single-crystal DRX measurements. Authors are thankful to the ANR as part of the "Investissements d'avenir " program (reference: ANR-10-EQPX-2801/Equipex ELORPrintTec).

\section{REFERENCES}

(1) Zhao, J.; Li, Y.; Yang, G.; Jiang, K.; Lin, H.; Ade, H.; Ma, W.; Yan, H. Efficient Organic Solar Cells Processed from Hydrocarbon Solvents. Nat. Energy 2016, 1, 15027. 
(2) Park, K. H.; An, Y.; Jung, S.; Park, H.; Yang, C. The Use of an n-Type Macromolecular Additive as a Simple yet Effective Tool for Improving and Stabilizing the Performance of Organic Solar Cells. Energy Environ. Sci. 2016, 9, 3464-3471.

(3) Kan, B.; Li, M.; Liu, F.; Wan, X.; Yunchuang, W.; Wang, N.; Long, G.; Yang, X.; Feng, H.; Zuo, Y. et al. A Series of Simple Oligomer-like Small Molecules Based on Oligothiophenes for Solution-Processed Solar Cells with High Efficiency. J. Am. Chem. Soc. 2015, 137, 3886-3893.

(4) Deng, D.; Zhang, Y.; Wang, Z.; Zhu, L.; Fang, J.; Xia, B.; Wang, Z., Lu, K.; Ma, W.; Wei, Z. Fluorination-Enabled Optimal Morphology Leads to over 11\% Efficiency for Inverted Small-Molecule Organic Solar Cells. Nat. Commun. 2016, 7, 13740.

(5) Po, R.; Roncali, J. Beyond Efficiency: Scalability of Molecular Donor Materials for Organic Photovoltaics. J. Mater. Chem. C. 2016, 4, 3677-3685.

(6) Osedach, T. P.; Andrew, T. L.; Bulović, V. Effect of Synthetic Accessibility on the Commercial Viability of Organic Photovoltaics. Energy Environ. Sci. 2013, 6, 711-718.

(7) Ni, W.; Wan, X.; Li, M.; Wang, Y.; Chen, Y. A-D-A Small Molecules for SolutionProcessed Organic Photovoltaic Cells. Chem. Commun. 2015, 51, 4936-4950.

(8) Carsten, B.; Szarko, J. M.; Son, H. J.; Wang, W.; Lu, L.; He, F.; Rolczynski, B. S.; Lou, S. J.; Chen, L. X.; Yu, Y. Examining the Effect of the Dipole Moment on Charge Separation in Donor-Acceptor Polymers for Organic Photovoltaic Applications. J. Am. Chem. Soc. 2011, 133, 20468-20475. 
(9) Liu, X.; Sun, Y.; Hsu, B. B. Y.; Lorbach, A.; Qi, L.; Heeger, A. J.; Bazan, G. C. Design and Properties of Intermediate-Sized Narrow Band-Gap Conjugated Molecules Relevant to Solution-Processed Organic Solar Cells. J. Am. Chem. Soc. 2014, 136, 5697-5708.

(10) Coughlin, J. E.; Henson, Z. B.; Welch, G. C.; Bazan, G. C. Design and Synthesis of Molecular Donors for Solution-Processed High-Efficiency Organic Solar Cells. Acc. Chem. Res. 2014, 47, 257-270.

(11) Wessendorf, C. D.; Schulz, G. L.; Mishra, A.; Kar, P.; Ata, I.; Weidelener, M.; Urdanpilleta, M.; Hanisch, J.; Mena-Osteritz, E.; Lindén, M. et al. Efficiency Improvement of Solution-Processed Dithienopyrrole-Based A-D-A Oligothiophene Bulk-Heterojunction Solar Cells by Solvent Vapor Annealing. Adv. Energy Mater. 2014, 4, 1400266.

(12) Usluer, Ö.; Abbas, M.; Wantz, G.; Vignau, L.; Hirsch, L.; Grana, E.; Brochon, C.; Cloutet, E.; Hadziioannou, G. Metal Residues in Semiconducting Polymers: Impact on the Performance of Organic Electronic Devices. ACS Macro Letters 2014, 3, 11341138.

(13) Felouat, A.; D’Aléo, A.; Fages, F. Synthesis and Photophysical Properties of Difluoroboron Complexes of Curcuminoid Derivatives Bearing Different Terminal Aromatic Units and a meso-Aryl Ring. J. Org. Chem. 2013, 78, 4446-4455.

(14) Chambon, S.; D’Aléo, A.; Baffert, C.; Wantz, G.; Fages, F. Solution-Processed Bulk Heterojunction Solar Cells Based on $\mathrm{BF}_{2}-$ Hydroxychalcone Complexes. Chem. Commun. 2013, 49, 3555-3557. 
(15) Scharber, M. C.; Sariciftci, N. S. Efficiency of Bulk-Heterojunction Organic Solar Cells. Progress Polym. Sci. 2013, 38, 1929-1940.

(16) Arjona-Esteban, A.; Krumrain, J.; Liess, A.; Stolte, M.; Huang, L.; Schmidt, D.; Stepanenko, V.; Gsänger, M.; Hertel, D.; Meerholz, K. et al. Influence of Solid-State Packing of Dipolar Merocyanine Dyes on Transistor and Solar Cell Performances. $J$. Am. Chem. Soc. 2015, 137, 13524-13534.

(17) Takacs, C. J.; Sun, Y.; Welch, G. C.; Perez, L. A.; Liu, X.; Wen, W.; Bazan, G. C.; J. Heeger, A. J. Solar Cell Efficiency, Self-Assembly, and Dipole-Dipole Interactions of Isomorphic Narrow-Band-Gap Molecules. J. Am. Chem. Soc. 2012, 134, 16597-16606.

(18) de Gier, H. D.; Jahani, F.; Broer, R.; Hummelen, J. C.; Havenith, R. W. A. Promising Strategy To Improve Charge Separation in Organic Photovoltaics: Installing Permanent Dipoles in PCBM Analogues. J. Phys. Chem. A 2016, 120, 4664-4671.

(19) Cook, S.; Ohkita H.; Kim, Y.; Benson-Smith, J. J.; Bradley, D. D. C.; Durrant, J. R. A Photophysical Study of PCBM Thin Films. Chem. Phys. Lett. 2007, 445, 276-280.

(20) Ali, M.; Abbas, M.; Shah, S. K.; Tuerhong, R.; Generosi, A.; Paci, B.; Hirsch, L.; Gunnella, R. Realization of Solution Processed Multi-Layer Bulk Heterojunction Organic Solar Cells by Electro-Spray Deposition. Org. Electron. 2012, 13, 2130-2137.

(21) D’Aléo, A.; Heresanu, V.; Giorgi, M.; Le Guennic, B.; Jacquemin, D.; Fages, F.; NIR Emission in Borondifluoride Complexes of 2'-Hydroxychalcone Derivatives Containing an Acetonaphthone Ring. J. Phys. Chem. C 2014, 118, 11919-11927. 